\title{
On Montel's theorem in several variables
}

\section{J. M. Almira and KH. F. Abu-Helaiel}

\section{ABSTRACT.}

Recently, the first author of this paper, used the structure of finite dimensional translation invariant subspaces of $C(\mathbb{R}, \mathbb{C})$ to give a new proof of classical Montel's theorem, about continuous solutions of Fréchet's functional equation $\Delta_{h}^{m} f=0$, for real functions (and complex functions) of one real variable. In this paper we use similar ideas to prove a Montel's type theorem for the case of complex valued functions defined over the discrete group $\mathbb{Z}^{d}$. Furthermore, we also state and demonstrate an improved version of Montel's Theorem for complex functions of several real variables and complex functions of several complex variables.

\section{REFERENCES}

[1] Almira, J. M., Montel's Theorem and subspaces of distributions which are $\Delta^{m}$-invariant, to appear in Numer. Funct. Anal. Optimization, (2013) DOI:10.1080/01630563.2013.813537

[2] Almira, J. M. and López-Moreno, A. J., On solutions of the Fréchet functional equation, J. Math. Anal. Appl., 332 (2007), 1119-1133

[3] Anselone, P. M. and Korevaar, J., Translation invariant subspaces of finite dimension, Proc. Amer. Math. Soc., 15 (1964), 747-752

[4] de Boor, C. and Ron, A., Polynomial ideals and multivariate splines, in Multivariate Approximation Theory IV, ISNM 90, C. Chui, W. Schempp, and K. Zeller (eds.), Birkhäuser Verlag (1989) 31-40

[5] Djoković, D. Z., Representation theorem for $\left(X_{1}-1\right)\left(X_{2}-1\right) \cdots\left(X_{n}-1\right)$ and its applications, Ann. Polon. Math. $22(1969 / 1970)$ 189-198

[6] Fréchet, M., Une definition fonctionelle des polynomes, Nouv. Ann., 9 (1909), 145-162

[7] Ger, R., On some properties of polynomial functions, Ann. Pol. Math., 25 (1971), 195-203

[8] Hyers, D. H., Isac, G. and Rassias, T. M., Stability of functional equations in several variables, Birkhäuser, 1998

[9] Jones, G. A. and Singerman, D., Complex functions. An algebraic and geometric viewpoint, Cambridge Univ. Press, 1987

[10] Kuczma, M., On measurable functions with vanishing differences, Ann. Math. Sil., 6 (1992), 42-60

[11] Kuczma, M., An introduction to the theory of functional equations and inequalities, Second Edition, Birkhäuser Verlag, 2009

[12] Lefranc, M., Analyse spectrale sur $\mathbb{Z}^{n}$, C. R. Acad. Sci. París, 246 (1958), 1951-1953

[13] Leland, K. O., Finite dimensional translation invariant spaces, Amer. Math. Monthly, 75 (1968) 757-758

[14] Mckiernan, M. A., On vanishing n-th ordered differences and Hamel bases, Ann. Pol. Math., 19 (1967) 331-336

[15] Montel, P., Sur quelques extensions d'un théorème de Jacobi, Prace Matematyczno-Fizyczne, 44 (1937), No. 1, 315-329

[16] Popa, D. and Raşa, I., The Fréchet functional equation with application to the stability of certain operators, J. Approx. Theory, 164 (2012), No. 1, 138-144

[17] Prager, W. and Schwaiger, J., Generalized polynomials in one and in several variables, Mathematica Pannonica, 20 (2009), No. 2, 189-208

[18] Székelyhidi, L., Discrete Spectral Synthesis and its Applications, Springer Monographs on Mathematics, Springer, 2006

[19] Székelyhidi, L., Convolution type functional equations on topological abelian groups, World Scientific, 1991

[20] Waldschmidt, M., Topologie des Points Rationnels, Cours de Troisième Cycle 1994/95 Université P. et M. Curie (Paris VI), 1995

Received: 30.10.2013; In revised form: 24.03.2014; Accepted: 23.04.2014

2010 Mathematics Subject Classification. 47A15, 46F05, 46F10, 39B22, 39B32.

Key words and phrases. Functional equations, Montel's theorem, invariant subspaces.

Corresponding author: J. M. Almira; jmalmira@ujaen.es 
Departamento DE MATEMÁTICAS

UNIVERSIDAD DE JAÉN, E.P.S. LINARES

C/ Alfonso X el SAbio, 28, 23700, Linares (JaÉn), Spain

E-mail address: jmalmira@ujaen.es; kabu@ujaen.es 